Etnográfica

Revista do Centro em Rede de Investigação em

Antropologia

vol. 21 (3) | 2017

Vol. 21 (3)

\title{
Fazendo compadre: relações de compadrio entre o povo indígena chiquitano
}

Making compadres: godparenting among the Chiquitano indigenous people

\section{Verone Cristina da Silva}

\section{(2) OpenEdition \\ Journals}

Edição electrónica

URL: https://journals.openedition.org/etnografica/5067

DOI: 10.4000/etnografica.5067

ISSN: 2182-2891

\section{Editora}

Centro em Rede de Investigação em Antropologia

\section{Edição impressa}

Data de publição: 1 outubro 2017

Paginação: 599-612

ISSN: 0873-6561

\section{Refêrencia eletrónica}

Verone Cristina da Silva, «Fazendo compadre: relações de compadrio entre o povo indígena

chiquitano», Etnográfica [Online], vol. 21 (3) | 2017, posto online no dia 24 março 2018, consultado o 09 fevereiro 2022. URL: http://journals.openedition.org/etnografica/5067 ; DOI: https://doi.org/10.4000/ etnografica. 5067

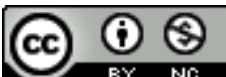

Etnográfica is licensed under a Creative Commons Attribution-NonCommercial 4.0 International License. 


\section{Fazendo compadre: relações de compadrio entre o povo indígena chiquitano}

\section{Verone Cristina da Silva}

O objetivo deste artigo é buscar, por meio de um exame etnográfico, o lugar que o compadrio ocupa na vida sociocosmológica do povo indígena chiquitano, falante da língua isolada chiquitano e que vive no Sudoeste de Mato Grosso, junto à fronteira entre o Brasil e a Bolívia. Pretende-se mostrar que, na concepção indígena, o compadrio é uma relação fabricada, orientada por regras, comensalidade, ritual e sociabilidade, que opera na passagem "da natureza à cultura" e nos processos de humanização da pessoa.

PALAVRAS-CHAVE: chiquitano, compadrio, pessoa, cosmologia, Mato Grosso, Brasil.

Making compadres: godparenting among the Chiquitano indigenous people - The article is focused on the role of relationships established through the godparenting of one's children within the socio-cosmological life of the Chiquitano indigenous people, who speak their own isolated language and live in southwest Mato Grosso, Brazil, close to the border with Bolivia. Based on ethnographic inquiry, the article shows that, in these indigenous people's view, godparenting (compadrio) is a constructed relationship, guided by certain rules and practices of commensality, ritual and sociability, and operating in the passage between "nature and culture" as well as in the person's humanization processes.

KEYWORDS: chiquitano, godparenting, person, cosmology, Mato Grosso, Brazil.

SILVA, Verone Cristina da (veronecristinadasilva@gmail.com). 
O POVO CHIQUITANO OCUPA OS DOIS LADOS DA FRONTEIRA ENTRE O Brasil e a Bolívia; é identificado, na literatura histórica, como remanescente de ameríndios que foram reunidos na Missão Jesuítica de Chiquitos, entre 1691 e 1767. ' Na República da Bolívia localizam-se, ao noroeste do departamento de Santa Cruz, nas províncias de Nuflo de Chaves, Velasco, Chiquitos e Sandoval, com uma população aproximada de 108.206 indivíduos; ao norte de Santa Cruz, no departamento de Beni. ${ }^{2}$ No Brasil, os chiquitano são identificados, no Mato Grosso do Sul, pelo etnônimo "camba" e, desde a década de 1980, estudos apontam a necessidade da demarcação da Terra Indígena Camba (G. J. Silva 2009: 20). No Mato Grosso, vivem aproximadamente 209 habitantes na Terra Indígena Portal do Encantado e, ainda, ao longo da fronteira entre Brasil e Bolívia, nos municípios de Cáceres, Porto Esperidião, Pontes e Lacerda e Vila Bela da Santíssima Trindade; calcula-se que a população pode chegar a 473 indivíduos. $^{3}$

O nascimento de uma criança chiquitano mobiliza muitos cuidados, principalmente das famílias, uma vez que se refere a um ser anônimo e suscetível a doenças provocadas por seres não humanos, espíritos de mortos atormentados ou seres encantados antropomorfos, que vivem solitários, à procura de humanos para capturá-los e transformá-los em seus pares, levando-os para mundos e paisagens subterrâneas. A criança recém-nascida é, portanto, vista como kurschananka (criatura, não humana) e os indígenas empreendem diferentes ações e cerimônias para transformá-la em krisrschtianoka (gente, humano, cristão).

A criança chiquitano nasce sem nome e sem dono, condição de tsauka (filho dos montes, bárbaro, não batizado), portanto, num estado de não humanidade. Após o rito batismal, este ser é nominado, torna-se gente, adquire a condição de tsaika (filho de Deus) e, desse modo, define-se o seu pertencimento a um dono.

A nominação da criança faz com que ela ganhe identidade, adquirindo assim a nausupürch ("alma-sombra”). Essa mudança de sua condição - de kurschananka para krisrschtianoka - cria outros laços de relações entre a criança, seus pais, os nominadores e os corresidentes. As pessoas que pronunciam o nome da criança pela primeira vez são chamadas de "padrinho e madrinha" e a criança será sua "afilhada".

Para a antropóloga Losonczy, que pesquisou negros e índios na Colômbia, os padrinhos (nominadores) e os progenitores da criança tornam-se conominadores e, desse modo, ocorre uma relação de "consanguinidade ritual" entre

1 Este artigo resulta da minha tese de doutorado em Antropologia Social, realizada na Universidade de São Paulo (V.C. Silva 2015).

2 Segundo dados do Censo 2012 disponibilizados pelo Instituto Nacional de Estatística da Bolívia em < https://www.ine.gob.bo/ > (última consulta em outubro de 2017).

3 Segundo dados da Funai e do Siasi-Funasa. 
eles, e uma relação de afiliação ritual entre os nominadores e o nominado; "de um ser indiferenciado de sua ascendência e sem nome próprio, a criança chocó se converte em um ser social nominado, com um parceiro codificado e sua identidade individual é ratificada pelo divino" (Losonczy 2006: 111-112) e, de alguma forma, a criança nasce pela segunda vez.

Entre os chiquitano, o convite dos pais aos futuros padrinhos e madrinhas dá-se após uma visita à casa do casal eleito. Ali, serão recitadas as seguintes palavras cerimoniais, pelo pai da criança: "Eu queria respeitar o senhor de compadre!" Em seguida, enfatiza a vontade de que sejam padrinho e madrinha de seu filho e indaga aos anfitriões se o aceitam. Os convidados dirão: "Sim, esse é o maior dos respeitos!” A partir de então, pais e padrinhos se abraçam e, juntos, seguem em direção à moradia da criança, onde será realizado o "batismo de água".

Renato Sztutman (2012: 142) argumenta que a apropriação do batismo, a exemplo dos tupis da costa do Brasil, no período colonial, foi intrinsecamente vinculada ao problema das epidemias. Os missionários eram vistos como tendo poderes de cura e perante a morte, além de se comunicarem com Jesus e os santos. "Batizar era xamanizar", obter cura e capacidade de curar; para ascender da Terra a um plano espiritual sem mal, seria preciso ser batizado, ser cristão. Como os missionários não compreendiam tal concepção, comparavam os pajés aos "missionários do demônio", pois eram capazes de curar e causar doenças. O antropólogo afirma que o rito batismal pode ser compreendido como uma prática "guerreira e xamanística", um dos maiores obstáculos à conversão dos índios, pois era tida pelos jesuítas como prática demoníaca, o que justificou muita repressão. $\mathrm{O}$ autor conclui que, se o batismo operado pelo padre fazia com que os índios se tornassem cristãos, o rebatismo, operado pelos caraíbas, fazia com que eles se tornassem santos. O batismo possibilitava ainda o deslocamento do campo da guerra para o do xamanismo, e o nome de santo produzia novas identidades. Tornar-se cristão consistia em uma forma de alcançar um patamar de imortalidade, apropriação da agência alheia para produzir socialidades, pessoas e grupos (Sztutman 2012: 448-449).

Uma de minhas interlocutoras, de sobrenome Chuê, explicou que, através do batismo, recebem o nome do santo do dia em que nasceram: "Santo é gente que viveu na Terra, possui força espiritual e protege os vivos de espíritos que causam doenças", e concluiu: "É um espírito auxiliar" (V.C. Silva 2015: 103). Um ancião chiquitano argumentou que os "santos eram os donos desta terra, pois não havia Deus. Eles são os principais, eles são naturais!”

O nome de santo para os chiquitano é um modo de adquirir uma força especial, capaz de protegê-los de seres que provocam doenças e ainda de feitiços. Por isso afirmam que "o que não tem nome [referindo-se aos recém-nascidos] é de quem aparece, porque ainda não está marcado, ainda não tem um dono”. Em um mundo ocupado por diferentes habitantes humanos e não humanos, 
o nome identifica o pertencimento da criança ao mundo dos humanos. A identificação da criança com o nome de santo é seguida pelo sobrenome indígena transmitido pelo pai e pelo sobrenome indígena da mãe.

Entre os chiquitano, não se recusa o convite para apadrinhar uma criança, a negativa é entendida como desprezo e abandono do recém-nascido, uma afronta aos pais, embora reconheçam que, em alguns casos, devido aos custos com a cerimônia, a roupa da criança, as velas e a festa, alguns poderiam recusá-lo; contudo, é possível que pais e padrinhos realizem a partilha das despesas. Mas, se uma pessoa solicita o apadrinhamento de uma criança, os pais tendem a negar tal pedido. Dizem que não é bom que seja assim, porque são os pais que devem oferecer a criança para "fazer compadre", esta é uma prerrogativa deles, faz parte da função dos pais nesta sociedade, para que, no futuro, os compadres não usem do seguinte argumento: "Eu não queria respeitar você de compadre!"

Na aldeia Vila Nova Barbecho, a relação de compadrio é fabricada ao longo da vida e a expressão nativa é "fazer compadre" - processo que tem início com o batismo, seguido da consagração da criança à Mãe de Jesus, da primeira eucaristia, do crisma, até, na fase adulta, o casamento. Para cada rito são escolhidos padrinhos e madrinhas distintos. Conheci uma jovem que tinha seis madrinhas e seis padrinhos e ainda uma mulher que possuía mais de 23 afilhados de famílias distintas. Ter afilhados é sinônimo de honra e prestígio, disse-me o vice-cacique; não tê-los indica o seu oposto.

Contudo, há outros modos de "fazer compadre". Uma moradia, antes de ser habitada deve ser batizada, nominada, para que seja protegida de seres não humanos que provocam doenças. Um homem e uma mulher são convidados pelo dono da moradia ("sombra"), a fim de apadrinhá-la, por meio das seguintes palavras cerimoniais: "Convidei os senhores para batizar minha sombra, para eu ser protegido do mal e para eu habitar nela". Os padrinhos devem subir até o esteio principal, cuja arquitetura possui a forma de uma cruz, e lá de cima derramar água para baixo e de ambos os lados. Após a cerimônia, os donos da moradia e os padrinhos tornam-se "compadres de nausupürch" ("sombra").

O compadrio de Carnaval é realizado pelos chiquitano no oitavo dia da cerimônia, momento chamado de "carnavalito" ou "enterro do carnaval". O personagem principal é um boneco confeccionado com folha de bananeira amarrada com fibras de taquara, que usa um pequeno chapéu sobre a cabeça e um charuto ou cigarro na boca, trajando uma calça comprida e camisa de manga longa, tendo por cima um vestido branco.

Os pais do "carnavalito" escolhem o padrinho (uma mulher travestida de homem) e a madrinha (um homem travestido de mulher) e pedem que batizem seu filho (o boneco) antes de enterrá-lo. A madrinha o carrega em seus braços, faz o sinal da cruz com um galho umedecido em água e o identifica com um nome, que deve ser masculino. Em seguida, pais e padrinhos cumprimentam-se 
como "comadre" e "compadre". O boneco, depois de permanecer nos braços da madrinha, é entregue à mãe; em seguida, é carregado pelo padrinho e depois pelo pai. Após a nominação do boneco, pais e padrinhos o depositam na cova. Os participantes lançam terra sobre o "morto" e fecham a cova, por fim modelam o túmulo. O nome do boneco, dos pais e dos padrinhos são registrados em um caderno, que permanece aos cuidados de uma liderança da comunidade.

Outra forma de "fazer compadre" é na festa de São João Batista, trata-se do "compadrio de fogueira", realizado durante a festa do santo. O fogo deve ser mantido através das lenhas da madeira angico para formar brasas, que devem permanecer acesas por um longo tempo. Aqueles que conseguirem caminhar sobre as brasas da fogueira, sem temor e, ainda, carregando o santo, tornam-se "compadres de fogueira" e têm como obrigação respeitarem-se e participarem da festa todos os anos.

O "compadre de aposta" é um acordo firmado entre duas pessoas antes de um jogo, sorteio ou disputas, quando uma das partes arrisca vencer ou perder. A iniciativa deve partir de um participante, que convida o parceiro para que se tornem "compadres"; desse modo, o resultado do jogo não implicará em inimizade entre os envolvidos.

Há, ainda, o "compadre de boneca" quando crianças brincam com suas bonecas, confeccionadas em tecido, para as quais realizam um batismo cerimonial, com água. Um menino e uma menina são convidados pela dona da boneca para serem "padrinho" e "madrinha", e um terceiro menino ocupa a posição de um padre. A madrinha presenteia a boneca com um vestido novo. O batismo ocorre com o derramamento de água sobre a cabeça da boneca, palavras cerimoniais e a sua nominação; as demais crianças participantes realizam uma festa e comem juntas. No entanto, essa variação do compadrio, embora proveniente de crianças, vale para a vida adulta, pois os chiquitano levam tais rituais muito a sério. O grau de importância do respeito entre compadres de batismo de um recém-nascido e do batismo de uma boneca são idênticos, como argumentou uma mulher que possui "comadres de boneca": "Basta dizer comadre que se cria o respeito".

O "compadre de respeito" ocorre entre duas pessoas que desejam se respeitar e evitar brigas entre si. O interessado convida outro para ser seu "compadre" e argumenta que este é o maior de todos os respeitos, cumprimentam-se tocando os ombros direitos, os ombros esquerdos e apertando as mãos; a partir desse momento, ambos seguirão as regras de respeito.

\section{NOÇÃO DE RESPEITO}

Uma anciã de sobrenome Macoño argumentou que a primeira regra do compadrio é o anaursch ("respeito"). E complementou: "Respeito ao compadre é espiritual. O compadrio não tem fim, é um laço eterno; a gente morre e o 
respeito continua”. O antropólogo Jürgen Riester (2008: 121-131), grande autoridade nos conhecimentos que adquiriu em mais de 40 anos com os chiquitano da Bolívia, observa que a consequência mais grave incorrida por aqueles que discutem, enfrentam ou brigam com os seus compadres seria sua conversão em pedras, localizadas no caminho das almas em direção ao Céu, ou, ainda, a permanência da alma do compadre agressor na Terra, perambulando pela aldeia.

O sentido nativo de "respeito" tem profundas consequências para os compadres, pois se institui como atemporal, o vínculo não se desfaz com a morte. Além disso, os compadres não podem brigar um com o outro, proferir palavras ou expressar gestos de desagrado, conversar livremente ou brincar, pois são comportamentos desaprovados, com claras interdições, tal como as relações sexuais são proibidas entre compadres e comadres. A relação de compadrio possui ainda uma dimensão política, permite acordos nas tomadas de decisões na aldeia, já que compadres tornam-se aliados entre si. Em reuniões, os compadres não questionam um ao outro e não se contrapõem; alguns preferem conversar e chegar a um acordo antes de se pronunciarem publicamente.

Uma mulher chiquitano, de sobrenome Rupe e da aldeia Fazendinha, me explicou o que seria o "respeito", recordando-se das orientações de sua mãe:

"Quando o pai e a mãe dançam, seus filhos não podem dançar. Se é a filha que dança, a mãe espera. Isso é respeito! É feio dançar filha e pai, podem se encostar, a filha tropeçar no pai, ou o pai na filha [...], sobrinha dançar com tio. Antes, se o filho via o pai bebendo, não bebia, respeitava, evitava as coisas, podiam travar e nem saber o que estão conversando. Se o filho estivesse bebendo e alguém dissesse: 'Convida, para o seu pai!', ele diria: 'Não, isso é um atrevimento'. Via o pai bêbado, carregava o pai e o levava para casa, assim estaria cuidando do pai, e nunca haveria briga entre pai e filho. Nunca o pai senta para beber com seu filho, e nunca o filho convida seu pai para beber".

A concepção de "respeito" é pautada por um conjunto de regras e interdições que institui o modo chiquitano de operar por meio de comportamentos de evitação. É uma categoria que prescreve "leis do incesto", como enfatizou uma anciã dos Macoño: "Deus deixou muitas leis para o respeito, para conhecer os parentes; o desrespeito provoca o mal, filhos de primos nascem com deficiência, tudo isso ficou de demonstração".

Na elaboração chiquitano, o compadrio parece ser o verdadeiro operador da passagem da natureza à cultura, ou da humanização, tanto dos bebês, quanto dos compadres; nesse entendimento, a nominação por meio do batismo torna a criança gente, mas é preciso que a humanidade seja mantida e assegurada - e ser "humano" é ter "respeito". 
A desobediência desta regra chiquitano resulta, portanto, em vergonha, e as sanções são doenças; nos casos graves, como relações incestuosas entre compadre e comadre, pai e filha, mãe e filho, irmão da mãe e filha da mãe, irmão do pai e filha do pai, haverá uma mudança do estado de humanidade para o de nichich (bicho), ser não humano, metamorfoseado, e sua expulsão da aldeia.

Os compadres ou comadres não se referem um ao outro pelo nome pessoal, sendo esta atitude compreendida como de desrespeito, sempre usam "compadre" ou "comadre", seguido do primeiro nome próprio. Durante as saudações, fazem uso de "senhor", "senhora", porém nunca "você"; o afilhado que se refere ao seu padrinho, deve identificá-lo por "padrinho", "o senhor". O uso de termos de parentesco - "mamãe", "papai", "tio" - e "compadre", "padrinho", "madrinha" - expressa "respeito" ou, dito de outro modo, evitação.

Nessa perspectiva, o "respeito" se opõe, fundamentalmente, à "brincadeira", compreendida como um operador que mobiliza práticas contrárias àquelas que ordenam a relação de evitação. A brincadeira seria o outro do respeito, na medida em que seus efeitos são contrastantes. É permitido brincar em contextos de proximidade e intimidade, tendo como alvo os parentes, porém este gesto não se estende àqueles com os quais o respeito é regra absoluta.

A relação de evitação e solidariedade entre duas pessoas kraô foi compreendida por Manuela Carneiro da Cunha (1978) como "amizade formal". O amigo formal seria um estranho, um não parente, a distância seria sua essência, podendo ainda ocorrer entre parentes que seguem tais regras sob pena de haver uma rutura do laço. O amigo formal pode gracejar e insultar suas vítimas, reafirmando sua estranheza. $\mathrm{O}$ duplo aspecto de evitação e parceria jocosa tende a definir esse amigo como aquele que nega e contradiz, sendo chamado para intervir em ritos de passagem e resguardo. Conclui a antropóloga que o amigo formal é o outro e sua presença atesta a dissolução da personalidade, restaura a identidade física e a posição social, se estendendo para a compreensão da noção de pessoa. Quando a amizade formal é associada ao compadrio, é a relação de evitação que se põe em primeiro plano.

O respeito entre compadres favorece acordos e evita a "briga" - como afirmou um chiquitano, basta dizer "compadre" que se institui o respeito recíproco. Uma briga entre parentes é aceitável, mas entre compadres é inadmissível regra observada também por Losonczy (2006: 117), ao se referir à "evitação mútua de ações mágicas" entre compadres. A "briga" tem ainda o sentido de feitiço (Figueiredo 2010).

Por este motivo, os chiquitano levam em conta vários aspectos na escolha dos compadres: serão pessoas que seguem as regras de respeito e reciprocidade; pessoas que compartilham dificuldades; pessoas ligadas por acordos firmados quando crianças por meio de jogos e brincadeiras, estendidos para a 
vida adulta; pessoas que andam juntas sobre as brasas de uma fogueira em um ritual festivo do santo de sua devoção; pessoas que querem permanecer amigas ou identificam a possibilidade de alguma inimizade ou um conflito, e então se previnem "fazendo compadre", como explicou um homem chiquitano de Vila Nova Barbecho: "parente pode brigar com outro parente, mas compadres ou comadres não; e, para não brigar, fazemos compadre". A raiva e a braveza são desaprovadas e perigosas; são concebidas como manifestações de seres não humanos, agindo e conduzindo a nausupürch ("alma-sombra") dos humanos e vivos, influenciando-a para agir a seu favor.

A palavra "compadre" e o abraço cerimonial em que os ombros tocam uns nos outros (direito com direito, esquerdo com esquerdo) transformam a pessoa e a relação, para toda a vida. Esta variação do "compadrio de respeito" potencializa o controle dos conflitos entre os corresidentes e os que vivem fora da aldeia.

Um antigo costume chiquitano era entregar três filhos de uma mesma família para um único casal batizar. A família $A$ entregava filhos para a família $B$, que retribuía com um ou mais filhos. Isto ocorreu com o músico Nicolau Urupe Jovió, que doou dois de seus filhos para Margarida Mocoño batizar e ela retribuiu, oferecendo-lhe dois de seus filhos. Este gesto era um modo de aumentar o respeito entre as famílias.

Os chiquitano preferem os corresidentes para apadrinhar seus filhos, ou pessoas de condições sociais próximas às suas. Contudo, há casos (não raros) de fazendeiros, comerciantes, militares, políticos e religiosos que vivem nas proximidades da aldeia, que a frequentam, ou para os quais os chiquitano tenham prestado algum serviço, com vínculos de trabalho, que são chamados a apadrinhar crianças ou casais em matrimônio; quase sempre são comprometidos com a festa, presentes, churrasco, roupas ou expectativas de auxílio futuro.

A escolha de um não indígena para padrinho, madrinha, compadre ou comadre constituiria uma exceção entre os chiquitano, por considerarem que não cumpririam as regras de reciprocidade e solidariedade que regem a relação ritual, uma vez que prevaleceria o critério econômico, cujo interesse estaria nos bens que a família do afilhado receberia e que a comunidade não poderia the fornecer (Riester 2008).

Os chiquitano dizem que o padrinho e a madrinha têm o mesmo direito que os pais na educação dos afilhados; devem lhes disponibilizar proteção, cuidado e correção. Em caso de falecimento dos pais, a criança afilhada poderá ficar sob os cuidados de seus padrinhos. Os afilhados têm obrigações para com seus padrinhos e madrinhas: ouvir suas palavras, seus conselhos; pedir a bênção (assim como pedem aos pais e irmãos de sua mãe e de seu pai, ou ainda aos estranhos). Se algum problema afetar a família, o padrinho e a madrinha serão chamados a opinar e o afilhado não poderá questioná-los, pois lhes deve total respeito. 
$\mathrm{Na}$ aldeia Vila Nova Barbecho, a mãe de um menino ainda pequeno permanece parte de seu tempo fora da aldeia por motivo de trabalho. Os cuidados e a socialização de seu filho passaram a ser responsabilidade da madrinha, já que o motivo se relaciona com a ausência da mãe. Durante o dia, o menino permanece na casa da madrinha e padrinho e, à noite, dorme em sua própria casa, em companhia do pai. Neste caso, os progenitores encontraram formas de o padrinho e a madrinha, que são responsáveis pela educação da criança, participarem desta atividade observando a evitação, pois não expõem demais a relação do padrinho com a mãe da criança, ou do pai com a madrinha.

Esta experiência nos remete ao estudo realizado por Peter Gow sobre os piro do Baixo Urubamba. De acordo com este antropólogo, o compadrio é um laço estabelecido entre pais e padrinhos destinado à educação da criança, a fim de criar outros conjuntos de relações entre corresidentes, o qual prevê regras e uma rede de cooperação no trabalho entre os homens. Os compadres são sempre como parentes reais e afins. É esperado que o padrinho seja gentil com seu afilhado ou sua afilhada, dê presentes e faça visitas. Espera-se, ainda, que os compadres bebam juntos mandioca fermentada, se respeitem mutuamente e não "brinquem" um com o outro. Além disso, uma pessoa deve estar sempre alegre para esperar seu compadre, que deve ter sempre aonde chegar - o compadre é bem-vindo como convidado (Gow 1991: 173).

\section{FILIAÇÃO RITUAL}

A escolha do padrinho e da madrinha de uma criança chiquitano obedece a regras prescritivas; a primeira é a de que sejam um homem e uma mulher casados, um homem e uma mulher solteiros ou, ainda, um viúvo e uma viúva, sempre aos pares. Se um homem solteiro apadrinhar uma criança, em companhia de uma madrinha casada com outro homem, a relação será entendida como incestuosa. Isto porque assumirão a copaternidade da criança. É mais comum a escolha de um homem e uma mulher casados, o que nos orienta a pensar que o critério se assemelha às regras ideais do que compreendem como um "bom casamento".

Para os chiquitano, um bom casamento é aquele entre um homem e uma mulher de sobrenomes indígenas distintos; ou seja, Muquissai casa-se com Tossuê, mas não se casa com Muquissai, porque são parentes. Os sobrenomes indígenas orientam casamentos, vida cerimonial e xamanismo entre as famílias do grupo local e as demais famílias das comunidades chiquitano no Brasil. Ao longo da fronteira entre Brasil e Bolívia são expressivos os sobrenomes Massavi, Tomichá, Manacá, Poché, Rodrigues, Poquiviviqui, Matata, Surubi, Pedrassa, entre outros.

Peter Gow (2003: 64) analisa que, entre os cocamas da Amazônia peruana, o sangue transmitido é marcado pela transmissão dos sobrenomes e estes estabelecem os limites do incesto. Em caso de mudança total de sobrenome, 
como ocorre com algumas moças da região, não se trata de "disfarçar suas identidades", mas de demonstrar interesse em abandonar seus laços de parentesco. No entendimento do antropólogo, o contato diário de mulheres cocamas com espaços domésticos de não indígenas e fazendas de "brancos", também identificados como "ricos", mudaria seus corpos aos seus próprios olhos e aos de seus parentes, pois sustentam que, nessa circunstância, seu sangue e traços corporais mudam efetivamente.

Tomando como referência Seeger, DaMatta e Castro (1979), Peter Gow reafirma que os corpos são feitos, construídos e transformados por meio do compartilhamento de substâncias, alimentos, palavras e doenças. Através do olhar do branco ou do rico, a mudança de nome da moça implica em não querer ficar perto de seus parentes, o que indicará, aos seus próprios olhos, sua crescente civilização e sua potencialidade como esposa fora da aldeia; a mudança de sobrenome registra, no plano onomástico, esta modificação (Gow 2003: 64-66).

Os sobrenomes chiquitano têm expressão direta na escolha de afins preferenciais para casamento. É preciso casar “entre iguais”, porém diferentes, e com alguém de sobrenome chiquitano. É possível que os sobrenomes correspondam a uma substituição das lógicas de identidade e diferença operantes num regime de maior dispersão espacial no contexto atual das comunidades. Se pensarmos que a distância, como propôs Viveiros de Castro (2002), opera como um gradiente no sistema de classificação de parentes, os sobrenomes marcariam essa diferença num raio de expansão de três gerações, como afirmam os indígenas. Neste entendimento, os sobrenomes chiquitano funcionam como um sistema de manutenção de diferenças internas e fronteiras externas do grupo, ainda que fluidas, num contexto de concentração populacional e risco de dissolução do grupo pelos casamentos com os de fora.

Assim que pais e padrinhos constroem relações de compadrio, logo se reconhecem por esse termo classificatório, que se estende para os demais parentes. O irmão do padrinho da criança será identificado como "tio" e, consequentemente, os filhos consanguíneos do padrinho serão seus "primos-irmãos". Os irmãos consanguíneos do "afilhado" serão "sobrinhos" do padrinho. O pai do padrinho da criança será seu "avô" e, por fim, o pai do pai de seu padrinho será identificado de "taita grande" ou "compadre". Este modelo se estende para os demais tipos de compadrio chiquitano (em lugar da criança, o elemento central poderá ser a casa, a boneca, ou outros).

Os chiquitano explicam que o compadre estaria na posição de irmão do pai ou da mãe, e a comadre na posição de irmã do pai ou da mãe, como afirmou um ancião de sobrenome Urupe: "Tio é como pai, tia é como mãe. Compadre é como pai, e entregamos nosso filho para respeitar essa pessoa [...]. Ele se apresentará na pessoa de Deus por esse padrinho. Respeito ao compadre é espiritual, não desejar falar mal". 
A genealogia chiquitano é orientada pela constituição geracional $(\mathrm{G}+3$ $=\mathrm{G}-3)$. E os anciãos da geração $\mathrm{G}+3$ e crianças da geração $\mathrm{G}-3$ se reconhecem por meio do termo "compadre"/"comadre", indicando um sistema cíclico e hierárquico. De acordo com o sistema chiquitano, o irmão do pai de Ego é tio primeiro, o irmão do avô de Ego é tio segundo, o pai do avô de Ego é tio terceiro e será chamado de "compadre", ou "taita/papai grande". Os anciãos da aldeia Vila Nova Barbecho afirmam que o termo nativo para bisavô (pai do avô) e bisneto (filho do neto) é "compadre". Argumentam ainda que "no Céu, taita é Deus, não se vê ele nascer, nem crescer; na Terra, taita é o compadre”.

Talvez a distância geracional já se apresente como um não parentesco, conforme afirmações piro (Gow 1991). Por outro lado, o ancestral e o padrinho parecem ser os superparentes, aqueles com quem se tem mais "respeito", marca do parentesco.

Entre os chiquitano, os parentes também criam relações de compadrio entre si. Uma mulher chiquitano que é comadre de sua irmã consanguínea, me explicou que, através da relação de compadrio, passaram a se identificar, reciprocamente, como comadres e deixaram de brincar e brigar uma com a outra, as visitas se tornaram mais frequentes e o tratamento é diferenciado. O termo de saudação entre as comadres passou a ser "senhora", em substituição do nome próprio, seguindo o mesmo protocolo de formalidade de outras comadres não aparentadas.

Tornar-se comadre para não brigar indica que o verdadeiro parente, aquele a quem se tem mais respeito, é o parente fabricado, ou mais marcadamente fabricado que os outros; basta dizer "comadre" para se respeitar.

Nas cerimônias de casamento, os pais do noivo tornam-se compadres dos pais da noiva; os pais dos pais dos noivos serão identificados como "vovô"/"vovó". Uma anciã chiquitano se recordou que, no tempo dos antigos, as esposas dos filhos das mães (noras) chamavam as sogras de "mamá" e prestavam serviços na casa, como filhas. E, desse modo, também os genros. Mas alertou que, atualmente, isso já não ocorre, o que lhe causa estranhamento.

Também cossogros são compadres; os parentes de uma pessoa devem ser tratados como parentes por seu cônjuge; o fato é comum na Amazônia, os afins são aqueles a quem se deve maior respeito, mas o respeito é também a marca das relações de parentesco. O casamento entre compadres e comadres é proibido, assim como entre primos de primeiro grau (chamados primos-irmãos), entre tios (irmãos da mãe ou do pai) e sobrinhas (filhas da irmã, do irmão da mãe, do irmão do pai). Estas relações estão sujeitas a sanções coletivas, vergonha e humilhação.

Outro importante componente nas cerimônias de compadrio é quando compadres comem juntos: o anfitrião, dono da casa, pai da criança ou do noivo, convida seu compadre à mesa para lhe servir chicha (bebida fermentada de mandioca) e alimento. 


\section{A "MESIADA": COMER JUNTO}

A comensalidade cerimonial é realizada nas principais festas da aldeia, havendo uma delas especialmente dedicada aos compadres, denominada "mesiada". A expressão tem como sentido "fazer uma mesa", "fazer um banquete", cujo sinônimo seria o de alimentar os compadres e, desse modo, afirmar a relação de respeito.

O dono da casa e progenitor convida seus compadres para irem a sua casa e sentarem ao redor de uma mesa onde são recebidos com um frango assado inteiro para cada um. Em lugar do frango inteiro, alguns chiquitano preparam o prato dos compadres com a coxa do frango sobre os demais alimentos. Quem serve os compadres é aquele que entregou o filho para que fosse por outro batizado. Nesse dia, o dono da casa anuncia em voz alta que o frango é um "carinho" aos seus compadres e o eleva para o alto, dizendo: "Viva os compadres!, Viva a Páscoa!" O compadre que recebe o prato já servido retira a coxa de frango e a eleva para o alto, dizendo: "Viva o dono da casa, viva a Páscoa!" Após esta cerimônia do "viva", os compadres comem o frango e, se não conseguirem comê-lo todo, repartem os pedaços com os parentes. O sentido literal das palavras cerimoniais recitadas pelo dono da casa é: "Viva, porque estamos vivos!" Um chiquitano Chue afirmou que o "viva" é dito em voz alta pelos compadres para que os espíritos (dos mortos) que estiverem próximos possam ouvir e, dessa forma, sair do meio ou se afastar, permanecendo à distância. "O viva é como dar um tapa no mal ou na morte", afirmou uma mulher Chue.

O "viva" é, primeiramente, proferido pelos compadres, em seguida pelos homens mais velhos e, por fim, pelas mulheres mais velhas. Além do frango, os anfitriões preparam chicha (bebida fermentada à base de mandioca) e servem os seus compadres; uma garrafa de bebida (cachaça) pode ser colocada sobre a mesa ou despejada num copo para que todos possam beber. Nesse dia, os compadres bebem muita chicha e são os primeiros a comer; em seguida, comem os adultos com os quais compartilham a mesa; por fim, comem as crianças, que estão em outra mesa, separada. Na Páscoa, havia ainda o "baile”, cujo som era produzido pelos músicos com a flauta, ao ritmo chovená, apropriado para se dançar em pares. Nessa cerimônia tocava-se também a flauta de Pã (navotich, seco-seco de três taquaras), feita com cinco tabocas perfiladas. Uma pessoa iniciava e a outra respondia aos toques (Pacini 2012: 49).

A "mesiada" deixou de ser realizada no Brasil; entretanto, os chiquitano criaram outros modos de manter o respeito aos compadres, como almoçarem juntos no barracão central da aldeia. 


\section{CONSIDERAÇÕES FINAIS}

O compadrio é um modo complexo de relação, muito estudado em comunidades rurais e urbanas, sendo definido como um sistema de relações rituais, com múltiplas variações, inclusive o batismo de influência cristã, a mais completa forma observada para criá-lo (Mintz e Wolf 1950; Gudeman 1971; Arantes 2011; Woortmann 1995).

O estudo do compadrio chiquitano propõe desafios à etnologia, na compreensão do modo de relação que opera na passagem da natureza à cultura e nos processos de humanização da pessoa, por vias diversas: nominação da criança, compadrio de batismo, compadrio de casa, de casamento, de fogueira, de boneca, de noivos, de aposta, de Carnaval.

O compadrio ocupa posição privilegiada na organização social e cosmológica chiquitano, podendo ocorrer em diferentes contextos e por meio de acordos entre as partes interessadas. Há diferentes tipos de compadrio para diferentes tipos de relações. Contudo, a principal regra é o "respeito" mútuo. O compadrio propõe a fabricação da alteridade, a produção do parentesco e a interdição de certas práticas entre os chiquitano. Por fim, cria um coletivo denominado "irmandade de respeito" - diferente de "família" e "parentes". A relação de compadrio não é encerrada com a morte, como bem lembrou um velho da aldeia: "Na Terra, todo mundo é compadre [irmão]. Depois da morte, todos continuam sendo compadres".

\section{BIBLIOGRAFIA}

ARANTES, Antonio A., 2011 , "Compadrio in rural Brazil: structural analysis of a ritual institution”, Vibrant, 8 (2): 70-1 12, disponível em < http://dx.doi.org/10.1590/S1809-434 $12011000200005>$ (última consulta em outubro de 2017).

CASTrO, Eduardo B. Viveiros de, 2002, A Inconstância da Alma Selvagem e Outros Ensaios de Antropologia. São Paulo, Cosac Naify.

CUNHA, Manuela Carneiro da, 1978, Os Mortos e os Outros: Uma Análise do Sistema Funerário $e$ da Noção de Pessoa entre os Krahó. São Paulo, Hucitec.

FIGUeIRedo, Marina Vanzolini, 2010, A Flecha do Ciúme: O Parentesco e Seu Avesso Segundo os Aweti do Alto Xingu. Rio de Janeiro. Museu Nacional/Universidade Federal do Rio de Janeiro, tese de doutorado em Antropologia Social.

GOW, Peter, 1991, Of Mixed Blood: Kinship and History in Peruvian Amazonia. Oxford, Oxford University Press. 
GOW, Peter, 2003, "Ex-cocama: identidades em transformação na Amazônia peruana", Mana, 9 (1): 57-79.

GUDEMAN, Stephen, 1971, "The compadrazgo as a reflection of the natural and spiritual person", Proceedings of the Royal Anthropological Institute of Great Britain and Ireland, 1971 : 45-71.

LOSONCZY, Anne-Marie, 2006, La Trama Interétnica: Ritual, Sociedad y Figuras de Intercambio entre los Grupos Negros y Emberá del Chocó. Bogotá, Instituto Colombiano de Antropologia e Historia/Instituto Francés de Estudios Andinos.

MINTZ, Sidney W., e Eric R. WOLF, 1950, "Analysis of ritual co-parenthood (compadrazgo)", Southwertern Journal of Anthropology, 6 (4): 341-368.

PACINI, Aloir, 2012, Identidade Étnica e Território na Fronteira (Brasil-Bolívia). Porto Alegre, Universidade Federal do Rio Grande do Sul, tese de doutorado em Antropologia Social. RIESTER, Jürgen, 2008, Contribución al Conocimiento de la Cultura de la Nación Indígena Chiquitana, vol. 2 (manuscrito).

SEEGER, Anthony; Roberto DaMATTA, e Eduardo Viveiros de CASTRO, 1979, "A construção da pessoa nas sociedades indígenas brasileiras", Boletim do Museu Nacional (n.s.), 32: 2-19.

SILVA, Giovani José da, 2009, A Presença Camba-Chiquitano na Fronteira Brasil-Bolívia (1938-1987): Identidades, Migrações e Práticas Culturais. Goiânia, Universidade Federal de Goiás, tese de doutorado em História.

SILVA, Verone Cristina, 2015, Carnaval: Alegria dos Imortais. Ritual, Pessoa e Cosmologia entre os Chiquitano no Brasil. São Paulo, Universidade de São Paulo, tese de doutorado em Antropologia Social.

SZTUTmAn, Renato, 2012, O Profeta e o Principal: A Ação Política Ameríndia e Seus Personagens. São Paulo, Edusp.

WOORTMAnn, Ellen F., 1995, Herdeiros, Parentes e Compadres: Colonos do Sul e Sitiantes do Nordeste. São Paulo/Brasília, Hucitec. 